
\title{
BReserch S Suare \\ Light-triggered hydrogen production from anhydrous alkaline methanol on a multi-layer device
}

\section{Yiou Wang ( $\square$ yiou.wang@lmu.de)}

Ludwig-Maximilians-University Munich

\section{En-Ping Yao}

Ludwig-Maximilians-University Munich

Jacek Stolarczyk

Ludwig Maximilian University of Munich https://orcid.org/0000-0001-7935-4204

Jochen Feldmann

Ludwig-Masimilians-University Munich

\section{Article}

Keywords: Turnover Frequency, Proton Source, Hole Scavenger, Particle Aggregation

Posted Date: December 22nd, 2020

DOl: https://doi.org/10.21203/rs.3.rs-116810/v1

License: (c) (1) This work is licensed under a Creative Commons Attribution 4.0 International License.

Read Full License 


\section{Light-triggered hydrogen production from anhydrous}

\section{alkaline methanol on a multi-layer device}

Yiou Wang*+, En-Ping $\mathrm{Yao}^{+}$, Jacek K. Stolarczyk*, Jochen Feldmann.

Chair for Photonics and Optoelectronics, Nano-Institute Munich, Department of Physics, Ludwig-Maximilians-Universität Munich, Königinstr. 10, 80539, Munich, Germany. *Email: yiou.wang@1mu.de, jacek.stolarczyk@physik.uni-muenchen.de.

Abstract: Hydrogen production from methanol has attracted substantial interest because of the clean combustion of hydrogen and the convenience of methanol in storage and transportation. However, it requires high-temperature and high-pressure conditions to reform methanol with water to hydrogen with high turnover frequency (TOF, e.g. $10^{4}$ moles of hydrogen per mole of Pt per hour). Here we show that hydrogen can be produced from anhydrous alkaline methanol with a remarkable TOF of $1.8 \times 10^{6}$ moles of hydrogen per mole of Pt per hour on a light-triggered multi-layer system under mild conditions. The performance is attributed to the use of anhydrous methanol as both the proton source and the hole scavenger in alkaline conditions. In contrast to a slurry system, we show that the proposed multi-layer system avoids particle aggregation, and it leads to the effective utilization of methanol, light and Pt active sites. This notable performance steps forward to the practical lighttriggered hydrogen generation.

Hydrogen is an excellent energy reservoir because of the high gravimetric energy density and clean

combustion to water ${ }^{1}$. However, the transport and storage of hydrogen, usually in tanks, remain the difficulty in the use of hydrogen ${ }^{2}$. In contrast, liquid fuels are more convenient to store and to transport and possess relatively high volumetric energy density ${ }^{3}$. Therefore, the in situ generation of the required hydrogen from inexpensive and stable liquid media offers a promising alternative and has attracted much attention ${ }^{4-7}$. The use of water as a proton source to produce hydrogen is 
known as water splitting, e.g. via photolysis or electrolysis under moderate conditions $\left(e . g .25^{\circ} \mathrm{C}\right.$ and $1 \mathrm{~atm})^{8,9}$. While very appealing, this is a challenging reaction both from thermodynamic and kinetic standpoints due to the significant required energy input $\left(\mathrm{H}_{2} \mathrm{O} \rightarrow \mathrm{H}_{2} \uparrow+\frac{1}{2} \mathrm{O}_{2} \uparrow, \Delta \mathrm{G}=\right.$ $+237 \mathrm{~kJ} / \mathrm{mol}$ ) and considerable intermediate energy barriers, respectively. Recent benchmarks in photocatalytic water splitting include the $\mathrm{SrTiO}_{3}$ : $\mathrm{La}, \mathrm{Rh} / \mathrm{Au} / \mathrm{BiVO}_{4}$ : Mo sheet with a solar-tohydrogen (STH) efficiency of $\sim 1 \%{ }^{10}$ and the $\mathrm{Rh} / \mathrm{SrTiO}_{3}$ : $\mathrm{Al}$ catalyst with a quantum efficiency of almost unity at 350-360 $\mathrm{nm}^{11}$. However, the turnover frequency (TOF) on active sites (e.g. noble metals such as platinum or rhodium) of these photocatalytic systems is low (e.g. 3,600 moles of hydrogen per mole $\mathrm{Rh}$ per hour on the $\mathrm{SrTiO}_{3}: \mathrm{Al}$ catalyst), indicating an unsatisfactory utilization of the active sites. Compared with water splitting, hydrogen evolution from thermal catalytic aqueous-phase reforming of methanol (APRM, $\mathrm{CH}_{3} \mathrm{OH}+\mathrm{H}_{2} \mathrm{O} \rightarrow \mathrm{CO}_{2} \uparrow+3 \mathrm{H}_{2}, \Delta \mathrm{G}=+9 \mathrm{~kJ} /$ $\mathrm{mol})$ is less endergonic and has reached an industrial-grade TOF $\left(1.8 \times 10^{4}\right.$ moles of hydrogen per mole of Pt per hour) on Pt/a-MoC catalyst ${ }^{3}$. However, heat-driven APRM usually occurs at 190$350{ }^{\circ} \mathrm{C}$ under pressures of 20-50 atm and releases carbon dioxide ${ }^{3,7,12}$. An ideal hydrogen production process should possess a high TOF under mild conditions with zero carbon emission, a combination which has not yet been reported in the literature.

Light-driven APRM systems, also known as the photocatalytic hydrogen production half-reaction, possess the potential to meet the requirements mentioned above since it can operate under room temperature and ambient conditions ${ }^{13}$. More importantly, the photocatalytic proton reduction to hydrogen on Pt active sites has been reported to proceed at the timescale of $10-900 \mu$ s, corresponding to a theoretical TOF of $10^{6}-10^{8}$ moles of hydrogen per mole of Pt per hour ${ }^{14}$. Although the recent developments have improved the hydrogen evolution rates by a few orders of magnitude, such remarkable TOF has never been achieved in photocatalysis. In photocatalytic 
hydrogen production, water is generally considered to be the proton source, while methanol is commonly used as a hole scavenger to promote the reduction of protons by electrons (Scheme 1a). Hydrogen production only from methanol under light offers a potential alternative solution if a high TOF can be reached. One favorable reaction to release hydrogen is the reforming of methanol with alkali: $\quad \mathrm{CH}_{3} \mathrm{OH}+2 \mathrm{NaOH} \rightarrow \mathrm{Na}_{2} \mathrm{CO}_{3}+3 \mathrm{H}_{2} \uparrow, \Delta \mathrm{G}=-123 \mathrm{~kJ} / \mathrm{mol}, \Delta \mathrm{H}=-38.5 \mathrm{~kJ} /$ mol). The reaction is exothermal ( $c f$. Scheme 1b), in contrast to an endothermal reaction in aqueous methanol solutions. In effect, the role of light is only kinetic to help overcome the energy barrier, and the reaction can proceed without the harsh high-temperature and high-pressure conditions.

a

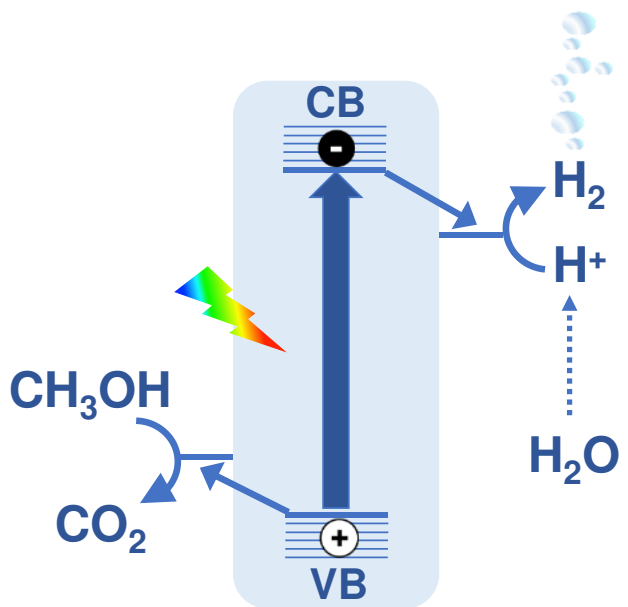

$\Delta \mathrm{G}>0 \quad \begin{aligned} & \text { Aqueous } \\ & \text { methanol }\end{aligned}$ b

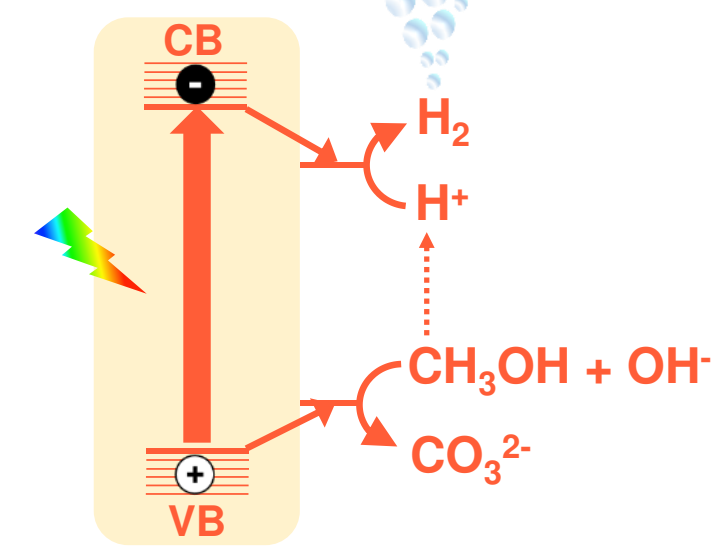

Anhydrous alkaline methanol
$\Delta \mathrm{G}<0$

Scheme 1. Photocatalytic hydrogen production from (a) methanol aqueous solution and (b) water-free alkaline methanol.

A slurry system, where catalysts disperse in a liquid medium, is the most commonly used system in photocatalysis ${ }^{15-18}$. However, a slurry system is difficult to scale-up, because it is constrained by the need for extra energy input for agitation to avoid the precipitation of the catalysts. It also suffers from the particle aggregation, non-uniform distribution of the catalyst and light-scattering 
$\operatorname{losses}^{19}$. Therefore, a non-slurry design might offer a more practical approach with controllable management of light and catalysts and a high TOF over active sites.

Herein, we report that hydrogen could be released from anhydrous alkaline methanol with TOF up to $1.8 \times 10^{6}$ moles of hydrogen per hour per mole of Pt and a hydrogen evolution rate of $1 \mu \mathrm{mol} / \mathrm{s}$ under the light on a multi-layer system. Such TOF is two orders of magnitude higher than that in thermal catalytic APRM. This unprecedented activity is due to the anhydrous alkaline methanol reaction and the multi-layer architecture of transparent membrane coated with photocatalysts, which avoids particle aggregation and tunes the light propagation without the need for agitation. Moreover, the system has zero carbon emission to the gas phase in that $\mathrm{CO}_{2}$ is captured in carbonate anions, hence paving an avenue to the practical use of photocatalytic hydrogen production.

\section{Results}

The design of the catalytic system. The idea of the present study is to immobilize the photocatalyst particles on the transparent polypropylene (PP) substrate for the reaction of methanol reforming to hydrogen under light (Fig. 1). Such a PP substrate could be folded into multi-layer structures to harvest the incident photons over the whole sample (Fig. 2). In this study, we focused on the hydrogen generation process instead of any specific materials. We hence chose two most well-documented materials, carbon nitride $(\mathrm{CN})$ and $\mathrm{TiO}_{2}$, as photocatalysts and commonly-used $\mathrm{Pt}$ as the co-catalyst. $\mathrm{CN}$ photocatalyst was synthesized from urea while $\mathrm{TiO}_{2}$ was commercial P25 without further treatment ${ }^{1,20-22}$. Experimental details can be found in the Supplementary information (SI). Briefly, a sheet of PP was folded into a 32-layer $2 \times 2 \mathrm{~cm}^{2}$ configuration as the 
substrate, cleaned with water and isopropanol and dried before being placed in an oxygen plasma cleaner to increase the hydrophilicity of the surface (Supplementary Fig. 1). Then, for example, 2 mg Pt/CN was loaded on both sides of the PP substrate and dried in an oven at $70^{\circ} \mathrm{C}$ before placing in a $30 \mathrm{ml}$ gas-tight reactor (Supplementary Fig. 1). The distribution of catalysts and thereby the light absorption have been carefully tailored by varying the loading of the catalyst and the number of the layers. PP hardly absorbs sunlight (Supplementary Fig. 2), ensuring that the loaded catalyst $\left(\mathrm{Pt} / \mathrm{CN}\right.$ or $\left.\mathrm{Pt} / \mathrm{TiO}_{2}\right)$ harvests most incident photons. From scanning electron microscopy (SEM) (Fig. 1c and Supplementary Fig. 3.a-b), CN clusters with a size of $2 \sim 10 \mu \mathrm{m}$ could be discerned on
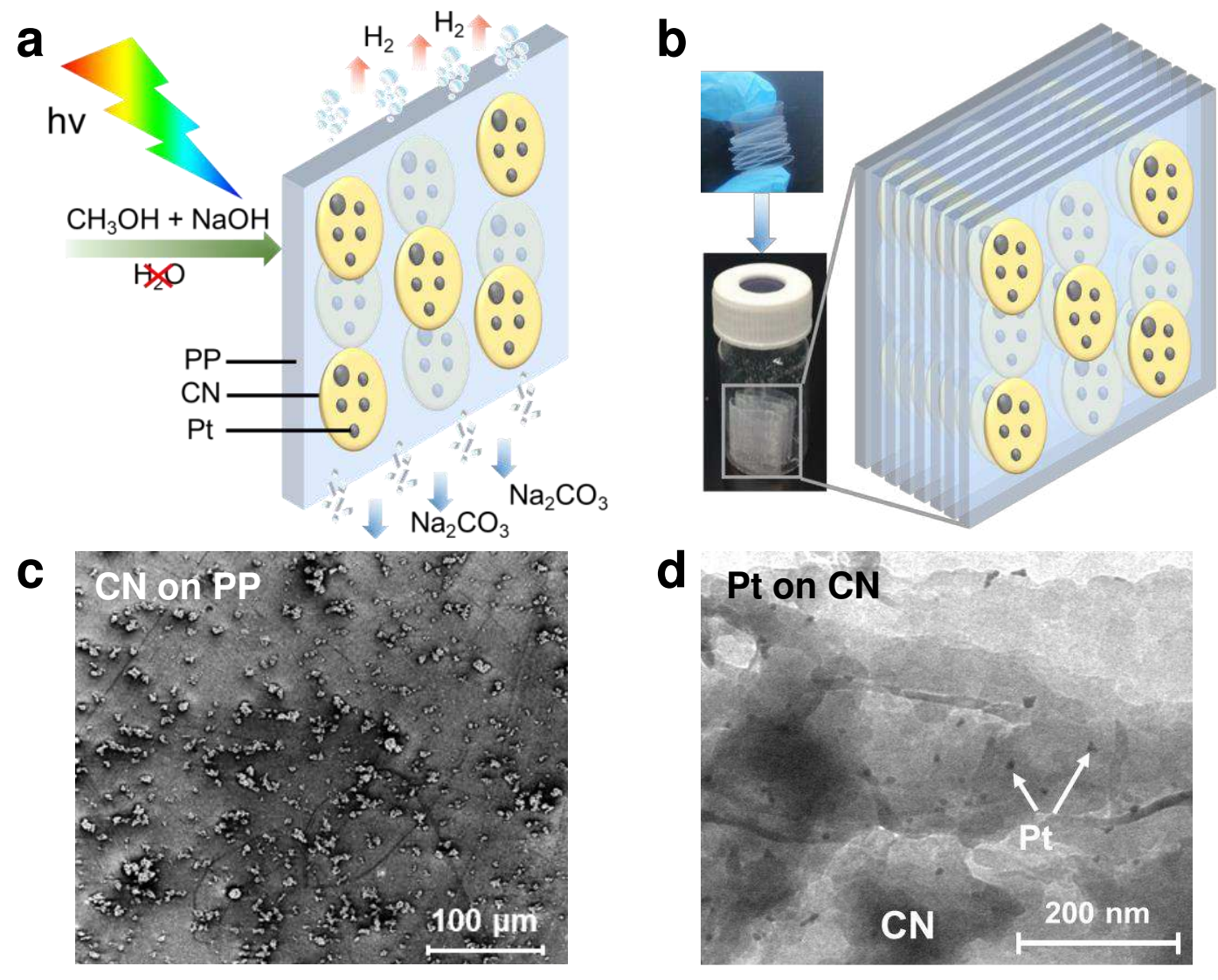

Fig. 1 Fabrication and characterizations of the multi-layer system. (a) The single PP layer decorated with Pt/CN for methanol reforming to hydrogen under the light. (b) The multi-layer membrane for methanol reforming to hydrogen. Inset: images of a bendable multi-layer membrane before and after deposition of Pt/CN. (c) SEM image of CN on PP membrane. (d) TEM image of Pt on CN. 
the PP substrate. The semiconductor photocatalysts were decorated with Pt via photodeposition ${ }^{20}$, where $\mathrm{Pt} / \mathrm{CN}$ represents $\mathrm{CN}$ decorated with $\mathrm{Pt}$, for instance. The transmission electron microscopy (TEM) images (Fig. 1d and Supplementary Fig. 3c) of Pt/CN show a stacked-layer morphology of $\mathrm{CN}$ and Pt clusters with a size of around 2-5 nm. The obtained $\mathrm{Pt} / \mathrm{CN}$ coating on $\mathrm{PP}$ remains robust even after rinsing by water and methanol.

Strong alkaline conditions were reported to prolong the lifetime of photogenerated electrons by quickly eliminating the holes ${ }^{16}$. According to our previous findings, the highly concentrated $\mathrm{OH}^{-}$ can rapidly react with photoholes to form hydroxyl radicals, which react with alcohol at a high rate $^{16}$. Hence, the slow hole transfer process is replaced with two faster ones, leaving long-lived electrons for the efficient reduction of protons to hydrogen ${ }^{16}$. By raising the $\mathrm{pH}$ (or decreasing the amount of water) in the system, the photocatalytic evolution rate of hydrogen was dramatically increased. The proposed reaction contains only sodium hydroxide, methanol and negligible water, which is a system with an extremely high $\mathrm{pH}$. The photocatalytic investigation was then carried out on the multi-layer system in a $10 \mathrm{ml}$ methanol solution containing $\mathrm{NaOH}$ under light irradiation.

The reforming of the alkaline methanol. We first measured the hydrogen production rates on $3 \%$ w.t. Pt/CN multi-layer sample in four $\mathrm{NaOH}$ methanol solutions containing $3 \%, 2 \%, 1 \%$ and $0 \%$ (v/v) water, respectively, to investigate the influence of water. As the amount of water decreased, both hydrogen production rates and TOF increased (Fig. 2a), due to the kinetically more efficient methanol deprotonation under more alkaline conditions ${ }^{16,23,24}$. It is important to note that aqueous methanol reforming is endothermal while the reforming of alkaline methanol is exothermal. The system with extra water is thermodynamically more challenging. In the absence of water, the 
sample evolved hydrogen at a rate of $241.7 \mu \mathrm{mol} / \mathrm{gs}$ with an average TOF of $6 \times 10^{3}$ moles of hydrogen per mole of Pt per hour, generating visible bubbles during the catalytic process (Fig. 2a and the Supplementary Video). Although no additional water was added in anhydrous methanol, water could be produced in situ by oxidation or deprotonation of methanol under highly alkaline conditions $^{16,24,25}$. Water is a widely-used proton source, however, extra water appears detrimental to photocatalytic hydrogen production from alkaline methanol, where methanol acts as both the proton source and the hole scavenger.
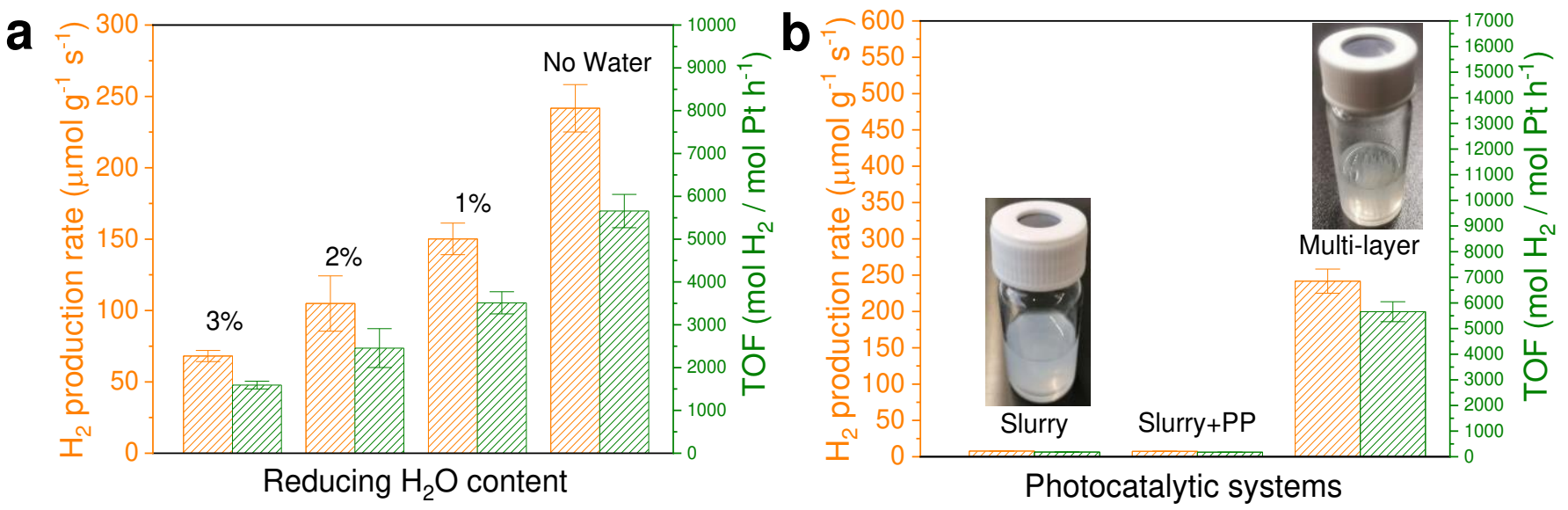

Fig. 2. Photocatalytic methanol reforming to hydrogen. (a) Hydrogen production rates and TOF as a function of the amount of water in the multi-layer system. (b) Hydrogen production rates and TOF of the multi-layer system ( 32 -fold), the slurry system and the slurry with PP flakes with inset images. The error bars represent standard deviations (SD).

In contrast to the multi-layer system, the conventional slurry system used as a reference showed 30 times lower hydrogen production rate and TOF (Fig 2b). Such a dramatic difference indicates that the well-distributed photocatalyst on the multi-layer system can utilize the incident photons much more efficiently compared to a slurry system under identical conditions. In the slurry system, the anhydrous alkaline methanol system also showed 20 times higher activity compared with a typical aqueous photocatalytic system containing 10\% methanol (Supplementary Table 1, Entry 5-6). To exclude the suspicion that the PP substrate might react with the $\mathrm{Pt} / \mathrm{CN}$, we sliced a piece 
of PP substrate (32-fold $2 \times 2 \mathrm{~cm}^{2}$, pre-treated under identical conditions). We added it into a reference Pt/CN stirred slurry (Fig. 2b). No significant improvement in the hydrogen production rate was observed, indicating the stability of the PP substrate. In the absence of Pt decoration, a membrane with $2 \mathrm{mg} \mathrm{CN}$ only released a tiny amount of hydrogen (Supplementary Fig. 4). In further control experiments (Supplementary Fig. 4 and Supplementary Table 1), negligible hydrogen was detected without light, catalysts or methanol, indicating that such an exothermal reaction is not spontaneous but need to be triggered by the incident photons. Illumination can naturally raise the temperature of a reactor to $60 \sim 70{ }^{\circ} \mathrm{C}^{13,26,27}$. Another possible reason for the temperature rise is due to the exothermic methanol reforming with alkali reaction. Thus, the temperature of the present system could also reach up to $70^{\circ} \mathrm{C}$. However, no catalytic activity was observed when the reactor was held at $70{ }^{\circ} \mathrm{C}$ under dark conditions (Supplementary Fig. 4), confirming that light is a necessary trigger.

In a multi-layer structure, when incident photons pass through the first front layer, only a fraction is absorbed by the small amount of catalysts on each side, while most photons reach the second layer. Some photons will be reflected to the first layer to excite the catalysts again while the rest is absorbed by the second layer or passes further (Supplementary Fig. 5a). As such, a multi-layer structure not only prevents aggregation of $\mathrm{CN}$ and reduces scattering but also enhances light utilization. The remote layers absorb fewer photons than the layers near the light source, so the amount of the catalyst and the number of layers should be balanced. Therefore, we tuned the number of stacking layers from 32 to 16 to 8 (2.0, 1.0 and $0.5 \mathrm{mg}$ of $\mathrm{Pt} / \mathrm{CN}$, respectively) to manage the light propagation inside the system. The optimal hydrogen production was achieved on a 16fold membrane (Supplementary Fig. 5b), and the TOF was further increased to $4.4 \times 10^{4}$ mole of hydrogen per mole of Pt per hour with a hydrogen formation rate of $189 \mu \mathrm{mol} / \mathrm{gs}$. 
Platinum is the cost determinant of such a methanol-reforming system. Excess Pt shields the surface of $\mathrm{CN}$ from incident photons and decreases the number of individual sites by forming large clusters. Therefore, it is crucial to use these active sites adequately to maximize the TOF. One method is to load Pt-decorated CN powder on the PP. In this case, some Pt sites were presumably embedded inside the $\mathrm{CN}$ clusters (Fig. 3a left), out of the reach of the protons at the methanol/CN interface and thus wasted for activity. Therefore, to decorate Pt selectively on the surface of $\mathrm{CN}$,

CN was first coated on the membrane. Then Pt was in situ photodeposited on CN (Fig. 3a right).
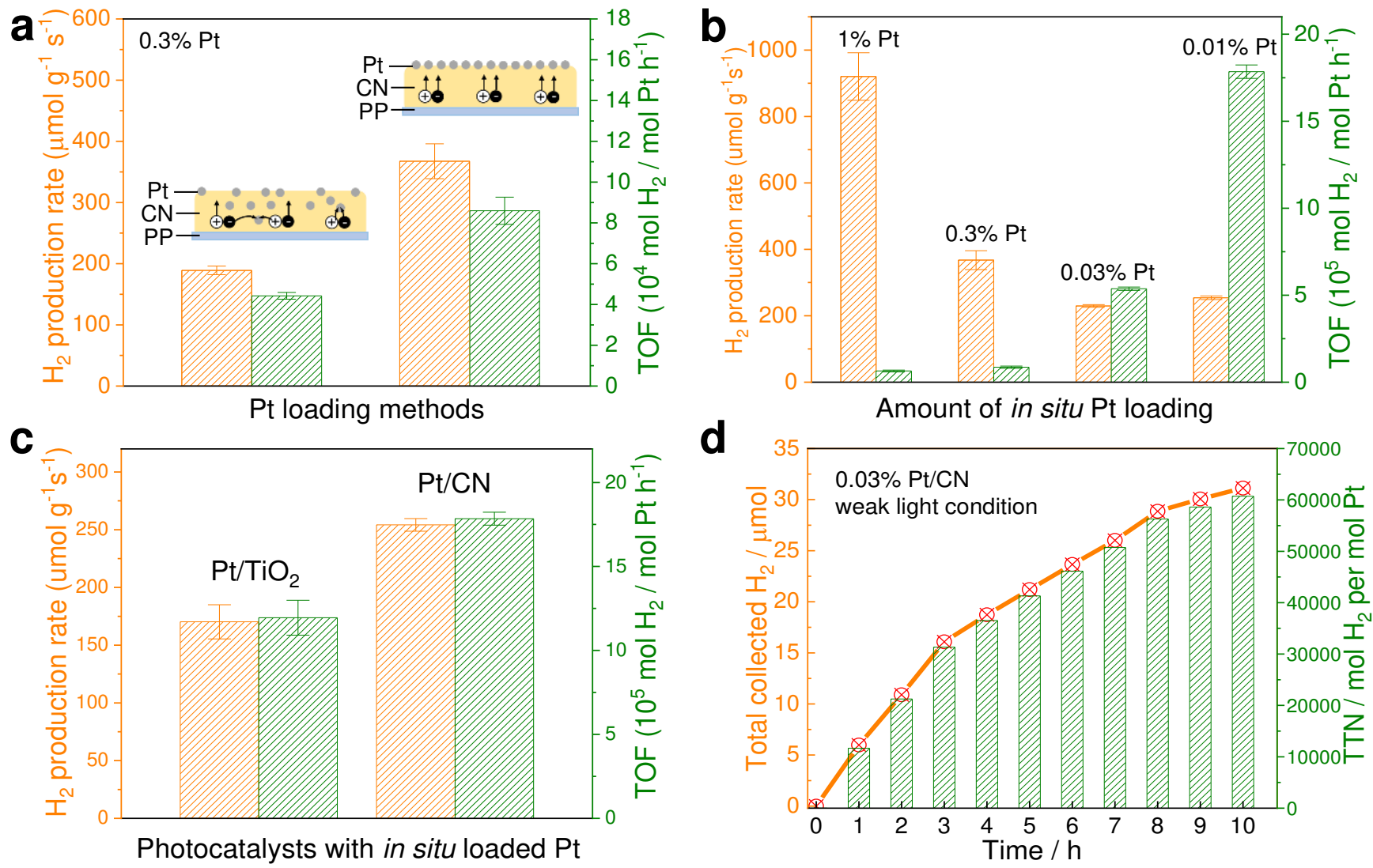

Fig. 3. Effect of various parameters on the multi-layer systems for methanol reforming. (a) Hydrogen production rates and TOF as a function of the Pt loading methods. Left: typical loading method, Pt dispersed randomly in CN. Right: in situ loading method, Pt selectively loaded on the interface of methanol/CN. (b) Hydrogen production rates and TOF as a function of the amount of Pt in situ loaded on $\mathrm{CN}$. (c) Hydrogen production rates and TOF as a function of different photocatalysts coated with in situ Pt co-catalyst. (d) Approaching long-term methanol reforming on $0.03 \% \mathrm{Pt} / \mathrm{CN}$ under weak light conditions. TTN: total turnover number. The error bars represent SD. 
With an identical amount of Pt (0.3\% w.t. CN), the in situ Pt loaded sample exhibited a doubled activity compared with the sample with Pt-decorated CN sample (Fig. 3a). As the loading ratio varied from $1 \%$ to $0.3 \%$, the TOF increased by $13 \%$ (Fig. 3b). Reducing the amount of Pt to $0.03 \%$ w.t. of $\mathrm{CN}$, the TOF reached $5 \times 10^{5}$ mole of hydrogen per mole of Pt per hour. Interestingly, the $0.01 \% \mathrm{Pt} / \mathrm{CN}$ sample produced hydrogen with a TOF reaching $1.8 \times 10^{6}$ mole of hydrogen per mole of Pt per hour with an internal quantum yield of $21 \%$ at $365 \mathrm{~nm}$. This dramatic enhancement is due to selective deposition of exposed Pt active sites on the surface of photocatalysts.

To investigate the compatibility of our system with different photocatalysts, we loaded $\mathrm{TiO}_{2}$ nanoparticles onto a multi-layer PP substrate using identical methods (Supplementary Fig. 5c). A reproducible hydrogen production rate of $170.2 \mu \mathrm{mol} / \mathrm{gs}$ was measured on $\mathrm{Pt} / \mathrm{TiO}_{2}$ (Fig. $3 \mathrm{c}$ and Supplementary Fig. 5d), corresponding to a TOF of $1.2 \times 10^{6}$ mole of hydrogen per mole of Pt per hour. The comparable performance observed on $\mathrm{Pt} / \mathrm{TiO}_{2}$, and $\mathrm{Pt} / \mathrm{CN}$ indicates that the key for the remarkable activity is the intrinsic beneficial anhydrous alkaline methanol reforming reaction and the multi-layer structure photocatalytic system. The present catalytic approach is a general method to speed up the hydrogen production from methanol, and it does not depend on special semiconductors. The hydrophilicity of semiconductors also influences the photocatalytic activities in aqueous systems. In this water-free system, semiconductors with low hydrophilicity might also be used for hydrogen production.

The practical potential of the system. Moreover, the long-term stability of such a multi-layer system loaded with $\mathrm{Pt} / \mathrm{CN}$ was evaluated. In a $30 \mathrm{ml}$ reactor, the rapid production of hydrogen markedly increases the pressure (c.a. $23.2 \mathrm{ml} \mathrm{H}_{2}$ produced per hour on $1 \mathrm{mg} 0.01 \%$ w.t. $\mathrm{Pt} / \mathrm{CN}$ ) 
when the long-term test was carried out on $0.01 \%$ w.t. Pt/CN under full light power. Therefore, to minimize the change in pressure, we decreased light intensity. With reduced light intensity, the activity remained an initial TOF of $1.2 \times 10^{4}$ moles of hydrogen per mole of Pt per hour, still comparable to the benchmark of thermal catalysis ${ }^{3}$. Such a system stayed robust for ten hours, demonstrating the potential for long-term use (Fig. 3d). The slight decline of TOF over ten cycles was owing to the reduced transparency of solution due to the generated $\mathrm{Na}_{2} \mathrm{CO}_{3}{ }^{28}$, which is poorly soluble in methanol (Supplementary Fig. 6). Such transparency issues could be addressed by effectively separating and recycling $\mathrm{Na}_{2} \mathrm{CO}_{3}$ from the system. The consumption of $\mathrm{NaOH}$ in the system also accounted for the decay in the activity.

Another additional advantage of the present system is the in situ collection of $\mathrm{CO}_{2}$. Negligible $\mathrm{CO}_{\mathrm{x}}$ $\left(\mathrm{CO}_{2}\right.$ or $\left.\mathrm{CO}\right)$ was detected in the gas phase during the reaction (Fig. S7), indicating that $\mathrm{CO}_{2}$ was captured into carbonate rather than directly emitted into the headspace. More importantly, the danger of presence of $\mathrm{CO}$ is mitigated. $\mathrm{CO}$, a well-known poison for the Pt catalysts ${ }^{29}$, is absent in this system, allowing for a clean feed of pure hydrogen for fuel cells. In particular, methanol could be sustainably produced via the reduction of $\mathrm{CO}_{2}{ }^{30-32}$ and the oxidation of methane ${ }^{33-35}$ while $\mathrm{NaOH}$ could be regenerated from $\mathrm{Na}_{2} \mathrm{CO}_{3}$ (see Supplementary Texts), making the present system economical and sustainable ${ }^{36}$.

Two reports have achieved $\mathrm{CO}_{\mathrm{x}}$-free liquid methanol photodecomposition to formaldehyde and hydrogen: $\mathrm{CH}_{3} \mathrm{OH} \rightarrow \mathrm{CH}_{2} \mathrm{O}+\mathrm{H}_{2}(8)^{37,38}$. Although it avoids the production of $\mathrm{CO}_{\mathrm{x}}$, it has been found not ideal in terms of $\mathrm{H}_{2}$ production activity ${ }^{37}$. The reported hydrogen evolution rates of these systems are relatively low $\left(320 \mu \mathrm{mol} \mathrm{g} \mathrm{g}^{-1} \mathrm{~h}^{-1}\right.$ and $617 \mu \mathrm{mol} \mathrm{g} \mathrm{g}^{-1}$, without reported TOF). The present study both prevents $\mathrm{CO}_{\mathrm{x}}$ release and reaches a very high hydrogen evolution rate (up to $3.5 \mathrm{~mol} \mathrm{~g}^{-1} \mathrm{~h}^{-1}$ ) and TOF. The superior performance in the present study is due to the intrinsic 
design of the reforming of alkaline methanol, which is based on a different strategy from the photodecomposition of methanol.
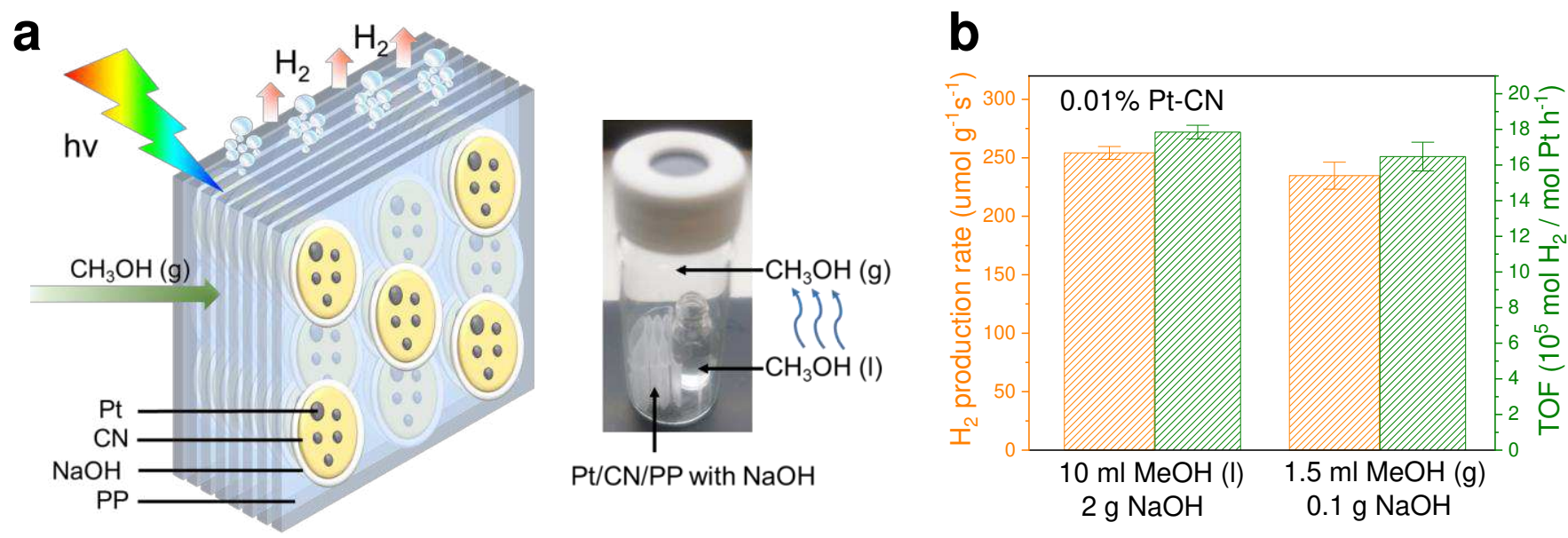

Fig. 4 Gas-phase methanol reforming on the multi-layer systems. (a) Left: schematic of the multi-layer membrane for gas-phase methanol reforming to hydrogen under light. Right: an image of the methanol vapor reforming setup on multi-layer membrane coated with $\mathrm{Pt} / \mathrm{CN} / \mathrm{NaOH}$. (b) Hydrogen production rates and TOF comparison on liquid-phase and gas-phase methanol reforming system. The error bars represent SD.

More strikingly, the multi-layer structure exhibited the activity to reform gas-phase methanol to hydrogen. Instead of using $10 \mathrm{ml}$ methanol solution, we placed a vial containing $1.5 \mathrm{ml}$ methanol to generate its vapor inside the reactor. $\mathrm{NaOH}$ was loaded together with $\mathrm{Pt} / \mathrm{CN}$ on $\mathrm{PP}$ (16-layer $0.01 \%$ w.t. Pt/CN), providing a local highly alkali-rich environment (Fig. 4a). Although the amount of reactants compared to the liquid-phase system was reduced, this gas-phase configuration still produces a comparable rate of hydrogen production. This implies a more efficient utilization of reactants than the liquid-phase one (Fig. 4b). The enhanced activity is attributed to the better contact between the catalyst particles and the methanol vapor. Such a gasphase methanol reforming system with a high TOF offers a potential solution to feed fuel cells in practical vehicles (see Supplementary Texts for further details). 


\section{Conclusion}

In summary, we have shown an efficient process to produce hydrogen from water-free alkaline methanol. We demonstrated that the reaction reaches a hydrogen evolution rate of $\sim 1 \mu \mathrm{mol} / \mathrm{s}$ and a TOF of $1.8 \times 10^{6}$ mole of hydrogen per mole of Pt per hour on multi-layer architecture loaded with $\mathrm{Pt} / \mathrm{CN}$ or $\mathrm{Pt} / \mathrm{TiO}_{2}$ under light illumination. The TOF is two orders of magnitude better than reported for the thermal catalytic approach. Herein, anhydrous methanol and alkali work as both the proton source and hole scavenger, where light has a kinetic role as a trigger for the reaction. In addition, the proposed layered system shows superior performance to the commonly-used slurry systems without the need for agitation. The high rate of hydrogen production is attributed to the intrinsic thermodynamically favorable reaction, the prevention of particle aggregation, the light management and the efficient utilization of Pt active sites. Moreover, the system could sustainably reform both liquid and gas phase of methanol to feed pure hydrogen to fuel cells. Furthermore, the earth abundance of raw materials for the plastic and urea, the ink-printing technique to deposit catalysts on the membrane and the compatibility of the gas-phase device with a flow system enable the scalable fabrication and hold promise for broad and practical applications.

\section{Methods}

\section{Material synthesis}

All chemicals are purchased from Sigma-Aldrich. In a typical carbon nitride synthesis, urea was placed in a lidded high-quality alumina crucible, then placed inside a furnace, and heated at a ramp rate of $5{ }^{\circ} \mathrm{C} \mathrm{min}{ }^{-1}$ and finally held at $600{ }^{\circ} \mathrm{C}$ for $4 \mathrm{~h}$. Water, $\mathrm{HCl}$, and $\mathrm{NaOH}$ were used to wash the produced powders to remove all unreacted and potentially detrimental surface species.

\section{Fabrication of a multi-layer membrane.}

$10 \mathrm{mg}$ carbon nitride powder (with or without Pt deposition) was dispersed in $15 \mathrm{ml}$ ethanol and sonicated $(50 \mathrm{~W})$ for 1 hour before use. To fabricate a multi-layer membrane, a piece of polypropylene substrate was folded to e.g. 16-fold of $2 \times 2 \mathrm{~cm}^{2}$ size and washed by water and isopropanol. Then it was dried at room temperature before placing in a plasma cleaner to promote the hydrophilicity of the surface. Then the folded membrane was placed into a $30 \mathrm{ml}$ reactor. The $\mathrm{CN}$-ethanol (or $\mathrm{Pt} / \mathrm{CN}$-ethanol) dispersion was added into 
the reactor and the membrane was submerged in the dispersion for 1 min to create the surface adsorption of the catalyst on PP. Then the dispersion was taken out and the wet membrane with surface adsorption of the catalyst was dried in an oven at $70^{\circ} \mathrm{C}$. The coating procedure was performed on both sides of the membrane for three times. Then the coated membrane was transferred to another clean $30 \mathrm{ml}$ reactor for photocatalysis.

\section{Photocatalyst characterization.}

UV/Vis absorption was measured with a Varian Carry 5000 UV-Vis-NIR spectrometer. The morphology of the photocatalyst was characterized by a JEOL JEM-1011 TEM operating at a $100 \mathrm{kV}$ accelerating voltage. High-resolution images in the TEM mode and the HAADF-STEM mode were recorded with an FEI Titan 80-300 operating at $300 \mathrm{kV}$.

\section{Photocatalytic reactions.}

The multi-layer membrane coated with $\mathrm{CN}$ was folded and place in a $30 \mathrm{ml}$ glass vial reactor (inner diameter $=25 \mathrm{~mm}$ ). $2 \mathrm{~g} \mathrm{NaOH}$ was dissolved in $10 \mathrm{ml}$ methanol to form the $\mathrm{NaOH}$ methanol solution. The solution was purified to remove $\mathrm{Na}_{2} \mathrm{CO}_{3}$ by centrifuge at $5000 \mathrm{rpm}$ for $5 \mathrm{~min}$. Then the clear solution was added to the $30 \mathrm{ml}$ reactor and purged with Argon for $15 \mathrm{~min}$ before placing under the light irradiation of $450 \mathrm{~W}$ Xenon lamp (FL-1039/40, AUX LAMP). In a typical slurry system (with $600 \mathrm{rpm}$ agitation under ambient conditions $25^{\circ} \mathrm{C}$ ), $2 \mathrm{mg} \mathrm{Pt} / \mathrm{CN}$ nanoparticles were dispersed in $10 \mathrm{ml} \mathrm{NaOH}$ methanol solution in a $30 \mathrm{ml}$ glass vial.

For the typical photodeposition method, a certain amount of $\mathrm{CN}$ powder with $\mathrm{H}_{2} \mathrm{PtCl}_{6}$ precursor was added into the reactor containing $10 \mathrm{ml} \mathrm{10 \%} \mathrm{methanol/water} \mathrm{solution,} \mathrm{sealed} \mathrm{and} \mathrm{purged} \mathrm{with} \mathrm{Ar}$ and irradiated by a 450W Xenon light source (FL-1039/40, AUX LAMP) for 2 hours. For the in-situ photodeposition method, CN was firstly coated on PP multi-layer membrane and placed in the reactor containing $10 \mathrm{ml}$ $\mathrm{NaOH}$ methanol solution, sealed and purged with Ar and irradiated by a $450 \mathrm{~W}$ Xenon light source (FL1039/40, AUX LAMP) for $12 \mathrm{~min}$. Then the reactor was purged with Ar again before evaluation of activity.

The system was purged by Argon before irradiation using a 450W Xenon light source (FL-1039/40, AUX LAMP). The headspace of the reactor was analyzed by Shimadzu GC2014 gas chromatography (GC) coupled with a thermal conductivity detector (TCD). Periodic measurements are taken manually by a syringe to determine the $\mathrm{H}_{2}$ production. For the evaluation of $\mathrm{H}_{2}$ generation, each time $10 \mu \mathrm{l}$ of the sample headspace was taken to the GC through Teflon-lined septum at the top of the reactor. The $\mathrm{H}_{2}$ formation rate is expressed as the molar amount evolved per second of illumination and per gram of catalysts. The $\mathrm{H}_{2}$ formation rates are calculated from the average values of at least 3 repeats for each sample. The error bars represent SD.

In a $\mathrm{NaOH}$ methanol solution slurry, the activity of hydrogen production reached $7.8 \mu \mathrm{mol} / \mathrm{gs}$, which is $\sim 20$ times higher than the commonly-used system with $10 \%$ methanol aqueous solution $(0.4 \mu \mathrm{mol} / \mathrm{gs})$. As such, the photocatalytic hydrogen generation rate measured on a $\mathrm{Pt} / \mathrm{CN}$ in $\mathrm{NaOH}$ methanol solution $(7.8 \mu \mathrm{mol} / \mathrm{gs})$ outnumbered the reported benchmark hydrogen evolution rates and TOF on Pt/CN $(3.6 \mu \mathrm{mol} / \mathrm{gs}$, Extended Data Table 1$)^{39}$, although the latter was measured under vacuum conditions, which often improves the hydrogen evolution yield significantly ${ }^{1,10}$.

\section{Calculation of internal quantum efficiency}

The internal quantum yields for Pt/CN photocatalyst was measured using $365 \mathrm{~nm}$ LED light. The internal quantum yields are defined by the following equation: IQY $=\frac{\text { number of reacted electrons }}{\text { number of the absorbed photons }} \times 100 \%$. Two electrons are consumed by per hydrogen molecule evolved: $2 \mathrm{e}^{-}+2 \mathrm{H}^{+} \rightarrow \mathrm{H}_{2}$. As a result, the internal 
quantum efficiency can be estimated by the equation: IQY $=\frac{\mathrm{N}_{\mathrm{H} 2} \times 2 \times N_{\mathrm{A}}}{\mathrm{H}_{\mathrm{a}} \times \mathrm{A} \times \frac{\lambda}{h c} \times t}$, where: $\mathrm{N}_{\mathrm{H} 2}$ is the amount of hydrogen under time $\mathrm{t}(\mathrm{s}), \mathrm{N}_{\mathrm{A}}$ is the Avogadro's number, $\mathrm{H}_{\mathrm{a}}$ is the average intensity of absorbed light, obtained by the subtraction of the transmitted intensity from the incident intensity measured by a detector . $\mathrm{A}$ is the irradiation area $\left(4 \mathrm{~cm}^{2}\right), h$ is the Planck's constant, $\mathrm{c}$ is the speed of light, $\lambda$ is the wavelength of the incident light, $\mathrm{t}$ is the time.

\section{Calculation of turnover frequency (TOF)}

The TOF is calculated from the hydrogen production amount $\left(\mathrm{R} \mu \mathrm{mol} / \mathrm{s} \times 10^{-6} \times 3600 \mathrm{~s} / \mathrm{h}\right)$ and $\mathrm{Pt}$ amount (mol) as follows:

$$
\mathrm{TOF}=\frac{R \mu \mathrm{mol} / \mathrm{s} \times 10^{-6} \times 3600 \mathrm{~s} / \mathrm{h}}{\text { Pt mol }}
$$

For example, for the $0.01 \% \mathrm{Pt} / \mathrm{CN}$ sample, $0.51 \mathrm{nmol} \mathrm{Pt}$ was added in the system. Meanwhile, $93.6 \mu \mathrm{mol}$ $\mathrm{H}_{2}$ was produced during a 6 -min irradiation. The turnover number is thus $1.84 \times 10^{5}$ during 6 minutes, corresponding to a TOF of $1.84 \times 10^{6} \mathrm{~mol} \mathrm{H}_{2}$ per mol Pt per hour. The TOF is calculated from the average of at least 3 repeats for each sample.

\section{Chemical reactions involved in the main text}

Methanol production from $\mathrm{CO}_{2}$ and water (1) and methanol aqueous reforming to hydrogen (2), which stepwise release oxygen and hydrogen, add up to water splitting (3).

$$
\begin{aligned}
& \mathrm{CO}_{2}+2 \mathrm{H}_{2} \mathrm{O} \rightarrow \mathrm{CH}_{3} \mathrm{OH}+\frac{3}{2} \mathrm{O}_{2} \\
& \mathrm{CH}_{3} \mathrm{OH}+\mathrm{H}_{2} \mathrm{O} \rightarrow \mathrm{CO}_{2} \uparrow+3 \mathrm{H}_{2} \uparrow \quad \Delta \mathrm{G}=+9 \mathrm{~kJ} / \mathrm{mol} \\
& \mathrm{H}_{2} \mathrm{O} \rightarrow \mathrm{H}_{2} \uparrow+\frac{1}{2} \mathrm{O}_{2} \uparrow \quad \Delta \mathrm{G}=+237 \mathrm{~kJ} / \mathrm{mol} \quad(1)+(2)=(3)
\end{aligned}
$$

In photocatalysis, methanol is usually used as hole scavenger (4) to promote the hydrogen production from water by reduction of protons (5), where (4) and (5) add up to (2).

$$
\begin{aligned}
& \mathrm{CH}_{3} \mathrm{OH}+6 \mathrm{~h}^{+}+6 \mathrm{OH}^{-} \rightarrow \mathrm{CO}_{2} \uparrow+5 \mathrm{H}_{2} \mathrm{O} \\
& 2 \mathrm{H}^{+}+2 \mathrm{e}^{-} \rightarrow \mathrm{H}_{2} \uparrow
\end{aligned}
$$

In the present study, water-free methanol was used to produce hydrogen and fix $\mathrm{CO}_{2}$ into carbonate via (6).

$$
\mathrm{CH}_{3} \mathrm{OH}+2 \mathrm{NaOH} \rightarrow \mathrm{Na}_{2} \mathrm{CO}_{3} \downarrow+3 \mathrm{H}_{2} \uparrow \quad \Delta \mathrm{G}=-123 \mathrm{~kJ} / \mathrm{mol}
$$

\section{Potential approach to recycle $\mathrm{NaOH}$}

One may argue that $\mathrm{NaOH}$ is also a cost determinant. Here we propose a process to regenerate $\mathrm{NaOH}$. In the presence of $\mathrm{NaOH}$, this system captures $\mathrm{CO}_{2}$ and forms $\mathrm{Na}_{2} \mathrm{CO}_{3}$ precipitate. Besides using $\mathrm{Na}_{2} \mathrm{CO}_{3}$ for further purposes, it is envisaged that the collected $\mathrm{Na}_{2} \mathrm{CO}_{3}$ could also naturally react with earth abundant $\mathrm{Ca}(\mathrm{OH})_{2}$ to form $\mathrm{CaCO}_{3}$ due to its smaller solubility and regenerate $\mathrm{NaOH}$ via the process: $\mathrm{Na}_{2} \mathrm{CO}_{3}+$ $\mathrm{Ca}(\mathrm{OH})_{2} \rightarrow 2 \mathrm{NaOH}+\mathrm{CaCO}_{3} \downarrow$ (7). The collected $\mathrm{CaCO}_{3}$ could be directly buried to store $\mathrm{CO}_{2}$ and $\mathrm{NaOH}$ is produced.

$\mathrm{CaCO}_{3}$ could also be decomposed to $\mathrm{CaO}$ and $\mathrm{CO}_{2}$ under electro-thermal heating with the electricity produced by solar energy. Then $\mathrm{CaO}$ could be naturally converted to $\mathrm{Ca}(\mathrm{OH})_{2}$ again to regenerate $\mathrm{NaOH}$, while $\mathrm{CO}_{2}$ is released under control to e.g. produce methanol (1) again. Hence, the proposed cycle to regenerate $\mathrm{NaOH}$ can be completed. The overall total reaction is again carbon-neutral. Such a process 
involves all abundant and inexpensive reactants driven by renewable energy such as light and is therefore sustainable.

\section{Estimation of Pt usage for practical vehicles.}

Although how this strategy would work in practice is a complicated question related to both science and engineering, we still can roughly estimate the usage of $\mathrm{Pt}$ for a commercial proton-exchange membrane fuel cell (PEMFC) vehicle. The reported hydrogen consumption and range of the Toyota Mirai 2017 vehicle are $1 \mathrm{~kg} \mathrm{H}_{2}$ per $100 \mathrm{~km}$ (at a speed of about $100 \mathrm{~km} \mathrm{~h}^{-1}$ ) and $500 \mathrm{~km}$, respectively. To fuel such a vehicle, the fuel tank used in traditional cars could be filled with methanol. Given the hydrogen-consumption rate of Mirai $\left(1 \mathrm{~kg} \mathrm{~h}^{-1}\right)$ and the Pt-normalized hydrogen-production rate $\left(1,800,000 \mathrm{~mol} \mathrm{H}_{2}\right.$ per mol Pt per hour) of the $0.01 \% \mathrm{Pt} / \mathrm{CN}$ catalyst, around $54.2 \mathrm{mg} \mathrm{Pt}$ should meet the requirements of Mirai per hour, which corresponds to approximately $542 \mathrm{~g}$ of $0.01 \% \mathrm{Pt} / \mathrm{CN}$ catalyst. The present system requires much less $\mathrm{Pt}$ compared to the previous benchmark, which requires $6 \mathrm{~g} \mathrm{Pt}$, and 3,000 $\mathrm{g}$ catalyst to achieve the same hydrogen production rate ${ }^{3}$.

\section{Data availability}

Supporting data is available in the Supplementary Information. Raw data is available from the corresponding authors upon reasonable request.

\section{References}

1 Wang, Y. et al. Current understanding and challenges of solar-driven hydrogen generation using polymeric photocatalysts. Nat. Energy 4, 746-760 (2019).

2 Schlapbach, L. \& Züttel, A. Hydrogen-storage materials for mobile applications. Nature 414, 353358 (2001).

3 Lin, L. et al. Low-temperature hydrogen production from water and methanol using Pt/ $\alpha-\mathrm{MoC}$ catalysts. Nature 544, 80 (2017).

4 Steele, B. C. H. \& Heinzel, A. Materials for fuel-cell technologies. Nature 414, 345-352 (2001).

5 Turner, J. A. Sustainable Hydrogen Production. Science 305, 972-974 (2004).

6 Norskov, J. K. \& Christensen, C. H. Toward Efficient Hydrogen Production at Surfaces. Science 312, 1322-1323 (2006).

7 Nielsen, M. et al. Low-temperature aqueous-phase methanol dehydrogenation to hydrogen and carbon dioxide. Nature 495, 85 (2013).

8 Sherbo, R. S., Delima, R. S., Chiykowski, V. A., MacLeod, B. P. \& Berlinguette, C. P. Complete electron economy by pairing electrolysis with hydrogenation. Nat. Catal. 1, 501-507 (2018).

9 Lin, L. et al. Molecular-level insights on the reactive facet of carbon nitride single crystals photocatalysing overall water splitting. Nat. Catal. 3, 649-655 (2020).

10 Wang, Q. et al. Scalable water splitting on particulate photocatalyst sheets with a solar-tohydrogen energy conversion efficiency exceeding 1\%. Nat. Mater. 15, 611 (2016).

11 Takata, T. et al. Photocatalytic water splitting with a quantum efficiency of almost unity. Nature 581, 411-414 (2020).

$12 \mathrm{Yu}, \mathrm{K} . \mathrm{M}$. K. et al. Non-syngas direct steam reforming of methanol to hydrogen and carbon dioxide at low temperature. Nat. Commun. 3, 1230 (2012).

13 Zhao, J., Shi, R., Li, Z., Zhou, C. \& Zhang, T. How to make use of methanol in green catalytic hydrogen production? Nano Select. 1, 12-29 (2020).

14 Yamakata, A., Ishibashi, T.-a. \& Onishi, H. Water- and Oxygen-Induced Decay Kinetics of Photogenerated Electrons in $\mathrm{TiO}_{2}$ and $\mathrm{Pt} / \mathrm{TiO}_{2}$ : A Time-Resolved Infrared Absorption Study. J. Phys. Chem. B 105, 7258-7262 (2001).

15 Burger, B. et al. A mobile robotic chemist. Nature 583, 237-241 (2020). 
Simon, T. et al. Redox shuttle mechanism enhances photocatalytic $\mathrm{H}_{2}$ generation on Ni-decorated CdS nanorods. Nat. Mater. 13, 1013 (2014).

17 Lau, V. W.-h. et al. Rational design of carbon nitride photocatalysts by identification of cyanamide defects as catalytically relevant sites. Nat. Comm. 7 (2016).

18 Xiang, Q., Yu, J. \& Jaroniec, M. Synergetic Effect of $\mathrm{MoS}_{2}$ and Graphene as Cocatalysts for Enhanced Photocatalytic $\mathrm{H} 2$ Production Activity of $\mathrm{TiO}_{2}$ Nanoparticles. J. Am. Chem. Soc. 134, 6575-6578 (2012).

19 Romero, R. L., Alfano, O. M. \& Cassano, A. E. Cylindrical Photocatalytic Reactors. Radiation Absorption and Scattering Effects Produced by Suspended Fine Particles in an Annular Space. Ind. Eng. Chem. 36, 3094-3109 (1997).

20 Martin, D. J. et al. Highly Efficient Photocatalytic $\mathrm{H}_{2}$ Evolution from Water using Visible Light and Structure-Controlled Graphitic Carbon Nitride. Angew. Chem. Int. Ed. 53, 9240-9245 (2014).

21 Liu, J. et al. Metal-free efficient photocatalyst for stable visible water splitting via a two-electron pathway. Science 347, 970-974 (2015).

22 Wang, X. et al. A metal-free polymeric photocatalyst for hydrogen production from water under visible light. Nat. Mater. 8, 76-80 (2009).

23 Ouyang, S. et al. Surface-Alkalinization-Induced Enhancement of Photocatalytic $\mathrm{H}_{2}$ Evolution over SrTiO3-Based Photocatalysts. J. Am. Chem. Soc. 134, 1974-1977 (2012).

24 Wagner, F. T. \& Somorjai, G. A. Photocatalytic hydrogen production from water on Pt-free $\mathrm{SrTiO}_{3}$ in alkali hydroxide solutions. Nature 285, 559-560 (1980).

25 Wakerley, D. W. et al. Solar-driven reforming of lignocellulose to $\mathrm{H} 2$ with a $\mathrm{CdS} / \mathrm{CdO}_{\mathrm{x}}$ photocatalyst. Nat. Energy 2, 17021 (2017).

26 Wang, Q. et al. Oxysulfide photocatalyst for visible-light-driven overall water splitting. Nat. Mater. 18, 827-832 (2019).

27 Fang, S., Sun, Z. \& Hu, Y. H. Insights into the Thermo-Photo Catalytic Production of Hydrogen from Water on a Low-Cost $\mathrm{NiO}_{x}$-Loaded $\mathrm{TiO}_{2}$ Catalyst. ACS Catal. 9, 5047-5056 (2019).

28 Kawai, T. \& Sakata, T. Conversion of carbohydrate into hydrogen fuel by a photocatalytic process. Nature 286, 474-476 (1980).

29 Amphlett, J. C. et al. Hydrogen production by steam reforming of methanol for polymer electrolyte fuel cells. Int. J. Hydrog. Energy 19, 131-137 (1994).

30 Olah, G. A. Beyond Oil and Gas: The Methanol Economy. Angew. Chem. Int. Ed. 44, 2636-2639 (2005).

31 Graciani, J. et al. Highly active copper-ceria and copper-ceria-titania catalysts for methanol synthesis from $\mathrm{CO}_{2}$. Science 345, 546-550 (2014).

32 Wang, Y. et al. Unique hole-accepting carbon-dots promoting selective carbon dioxide reduction nearly $100 \%$ to methanol by pure water. Nat. Commun. 11, 2531 (2020).

33 Xie, J. et al. Highly selective oxidation of methane to methanol at ambient conditions by titanium dioxide-supported iron species. Nat. Catal. 1, 889-896 (2018).

34 Sushkevich, V. L., Palagin, D., Ranocchiari, M. \& van Bokhoven, J. A. Selective anaerobic oxidation of methane enables direct synthesis of methanol. Science 356, 523-527 (2017).

35 Liu, Z. et al. Water-promoted interfacial pathways in methane oxidation to methanol on a $\mathrm{CeO}_{2}$ $\mathrm{Cu}_{2} \mathrm{O}$ catalyst. Science 368, 513-517 (2020).

36 Goeppert, A., Czaun, M., Jones, J.-P., Surya Prakash, G. K. \& Olah, G. A. Recycling of carbon dioxide to methanol and derived products - closing the loop. Chem. Soc. Rev. 43, 7995-8048 (2014).

37 Liu, Z. et al. Room temperature stable $\mathrm{CO}_{\mathrm{x}}$-free $\mathrm{H}_{2}$ production from methanol with magnesium oxide nanophotocatalysts. Sci. Adv. 2, e1501425 (2016). 
38 Pang, Y. et al. Colloidal Single-Layer Photocatalysts for Methanol-Storable Solar $\mathrm{H}_{2}$ Fuel. Adv. Mater. 31, 1905540 (2019).

39 Zhang, G. et al. Tailoring the Grain Boundary Chemistry of Polymeric Carbon Nitride for Enhanced Solar Hydrogen Production and $\mathrm{CO}_{2}$ Reduction. Angew. Chem. Int. Ed. 131, 3471-3475 (2019).

\section{Acknowledgements}

This research work was supported by the Bavarian State Ministry of Science, Research, and Arts through the grant "Solar Technologies go Hybrid (SolTech)" and by the European Union's Framework Programme for Research and Innovation Horizon 2020 (2014-2020) under the Marie Skłodowska-Curie Grant Agreement No. 754388 (E.-P. Yao) and from LMU Munich's Institutional Strategy LMU excellent within the framework of the German Excellence Initiative (No. ZUK22). Y. Wang thanks the Alexander von Humboldt Foundation fellowship. We also thank Dr. He Huang for assistance on TEM measurements and video filming.

\section{Author contributions}

Y. W. prepared the materials and carried out the photocatalytic measurements. E.-P. Y. performed electron microscopy measurements. Y. W. and E.-P. Y. developed the multi-layer devices. Y. W. wrote the manuscript with input from E.-P. Y., J. K. S and J. F. All authors contributed to discussions. ${ }^{+}$These authors contributed equally.

\section{Competing interests}

The authors declare no competing interests.

\section{Additional information}

Correspondence and requests for materials should be addressed to Y.W and J. K. S. 


\section{Figures}
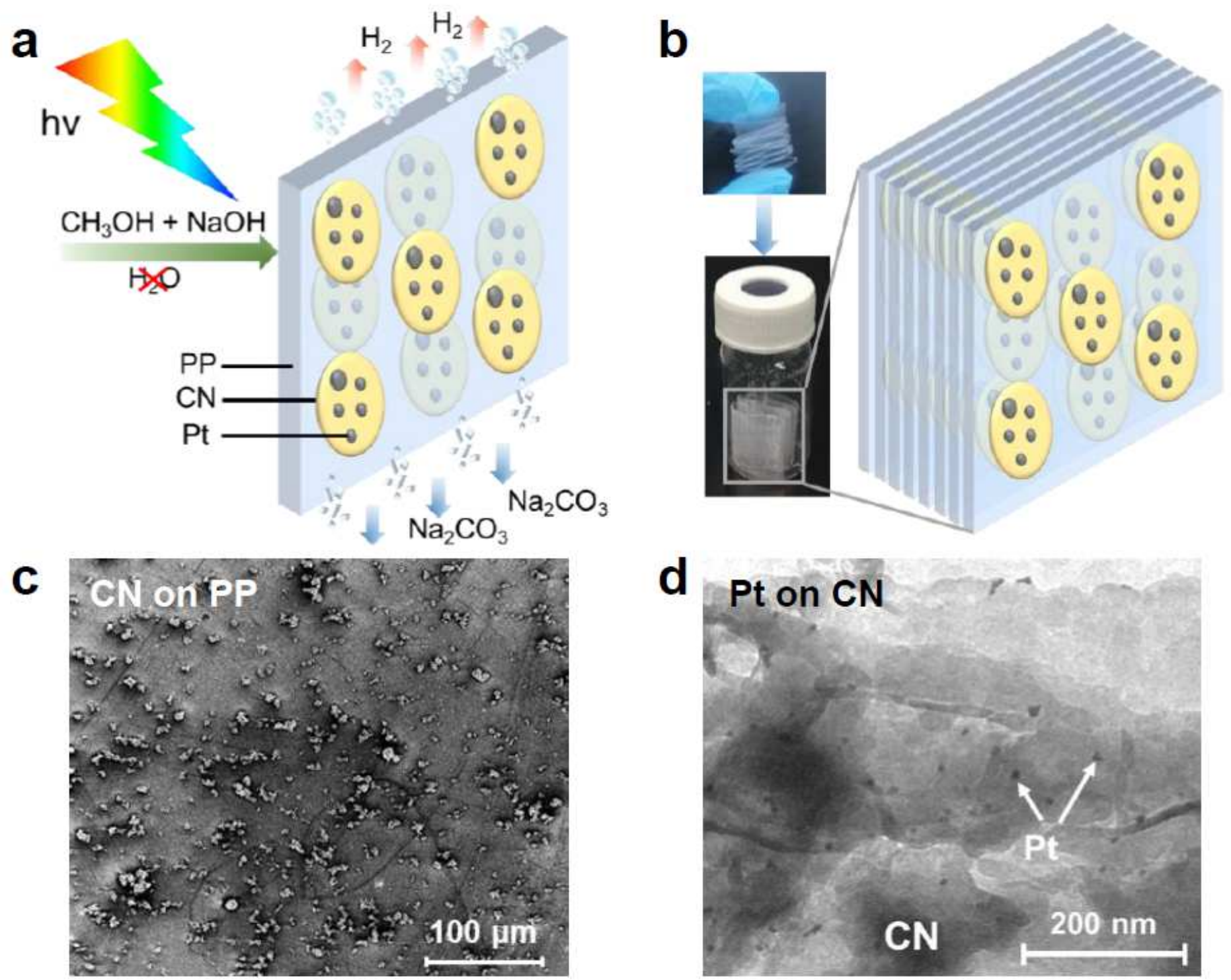

\section{Figure 1}

Fabrication and characterizations of the multi-layer system. (a) The single PP layer decorated with Pt/CN for methanol reforming to hydrogen under the light. (b) The multi-layer membrane for methanol reforming to hydrogen. Inset: images of a bendable multi-layer membrane before and after deposition of Pt/CN. (c) SEM image of CN on PP membrane. (d) TEM image of Pt on CN. 

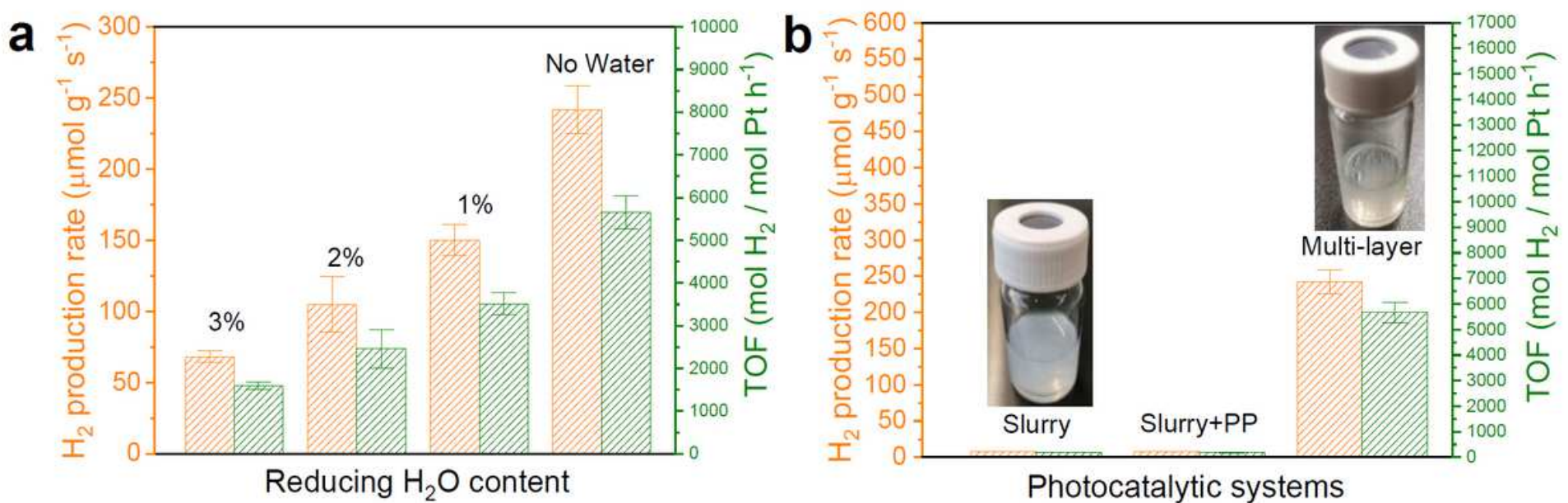

Figure 2

Photocatalytic methanol reforming to hydrogen. (a) Hydrogen production rates and TOF as a function of the amount of water in the multi-layer system. (b) Hydrogen production rates and TOF of the multi-layer system (32-fold), the slurry system and the slurry with PP flakes with inset images. The error bars represent standard deviations (SD).
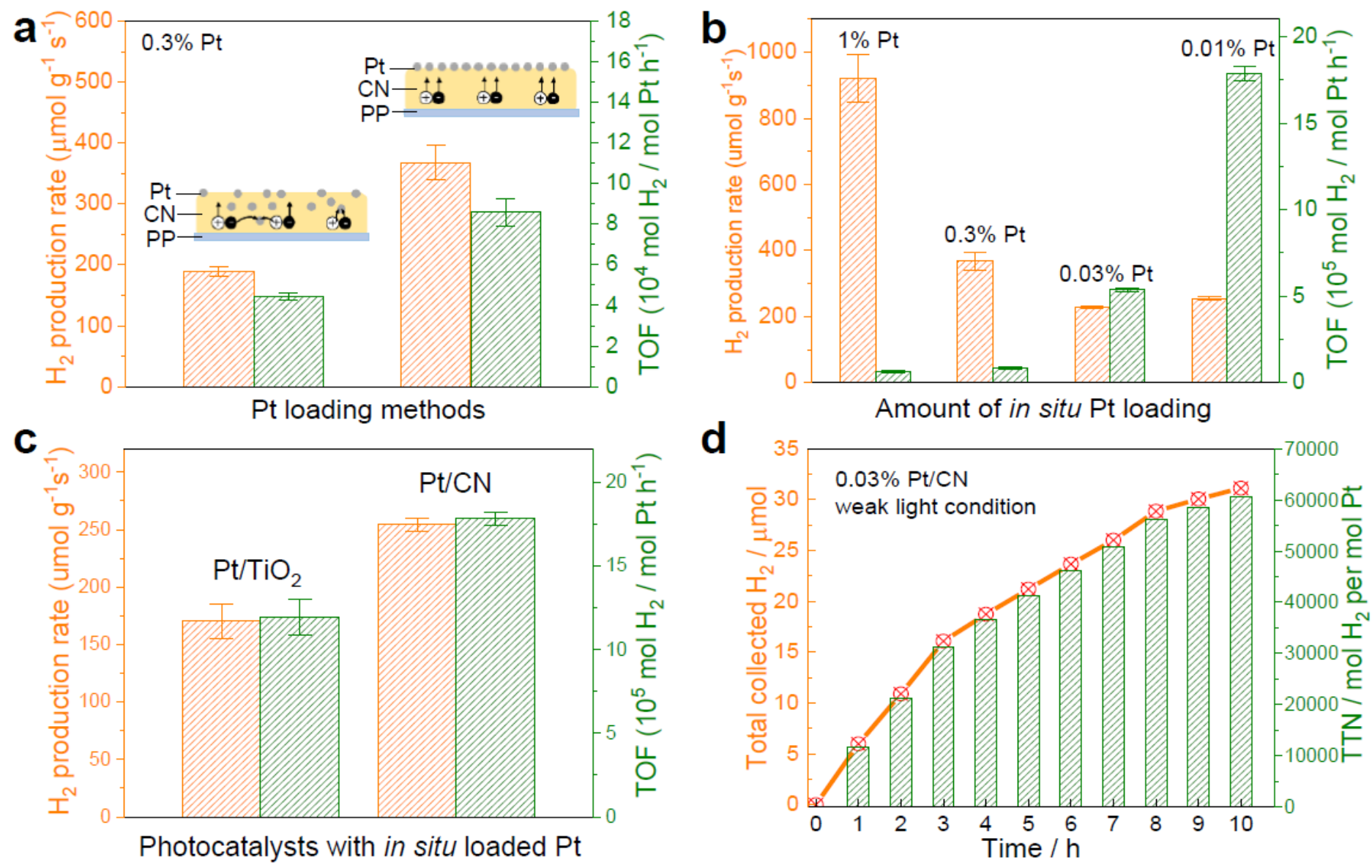

\section{Figure 3}


Effect of various parameters on the multi-layer systems for methanol reforming. (a) Hydrogen production rates and TOF as a function of the Pt loading methods. Left: typical loading method, Pt dispersed randomly in CN. Right: in situ loading method, Pt selectively loaded on the interface of methanol/CN. (b) Hydrogen production rates and TOF as a function of the amount of Pt in situ loaded on CN. (c) Hydrogen production rates and TOF as a function of different photocatalysts coated with in situ Pt co-catalyst. (d) Approaching long-term methanol reforming on $0.03 \% \mathrm{Pt} / \mathrm{CN}$ under weak light conditions. TTN: total turnover number. The error bars represent SD.
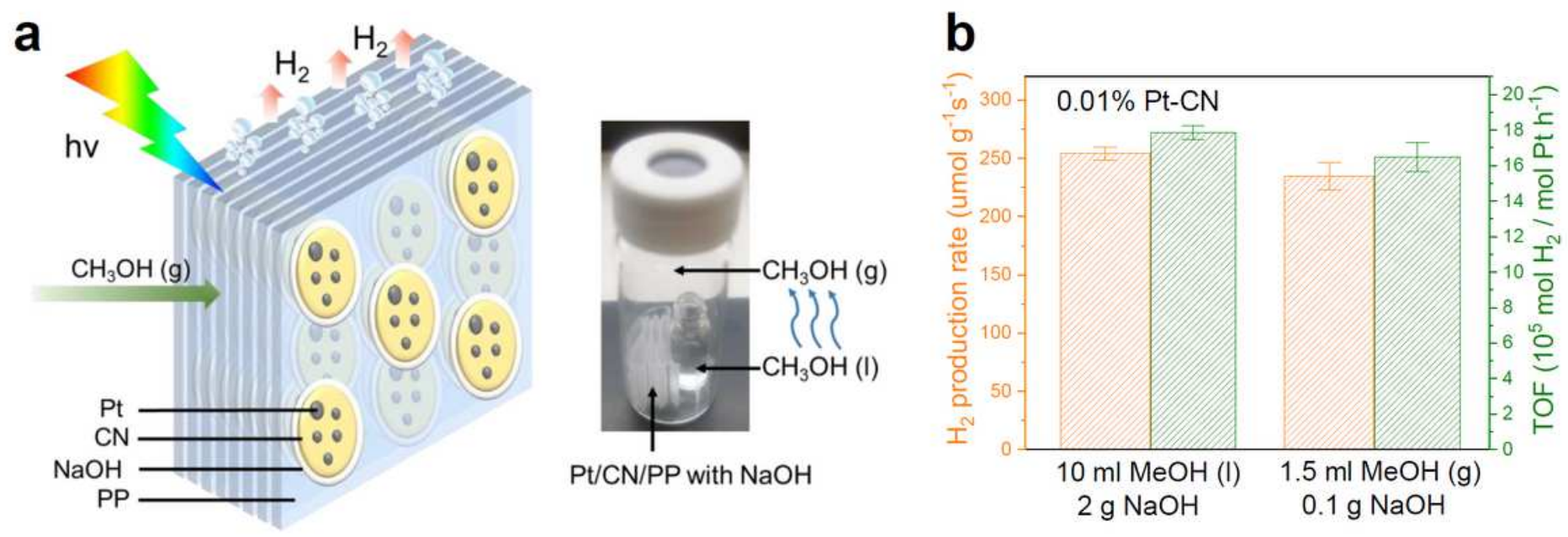

\section{Figure 4}

Gas-phase methanol reforming on the multi-layer systems. (a) Left: schematic of the multi-layer membrane for gas-phase methanol reforming to hydrogen under light. Right: an image of the methanol vapor reforming setup on multi-layer membrane coated with $\mathrm{Pt} / \mathrm{CN} / \mathrm{NaOH}$. (b) Hydrogen production rates and TOF comparison on liquid-phase and gas-phase methanol reforming system. The error bars represent SD.

\section{Supplementary Files}

This is a list of supplementary files associated with this preprint. Click to download.

- SupplementaryVideo.mp4

- Supplementaryinformation.pdf 